\section{IMPLEMENTAÇÃO DE SEQUÊNCIA DIDÁTICA EXPERIMENTAL NA PERSPECTIVA DA LUDICIDADE: CONSTRUINDO SABERES SOBRE $\mathbf{p H}$}

Implementation of experimental didactic sequence in the perspective of ludicity: building knowledge about $\mathrm{pH}$

Implementación de la secuencia didáctica experimental en la perspectiva de Ludicidade: Construyendo conocimiento sobre el $\mathrm{pH}$

\section{Resumo}

Este trabalho relata uma investigação no Ensino de Ciências com base em uma sequência didática construída a partir da associação entre experimentos e jogos, com a finalidade de analisar criticamente a inserção de ludicidade para auxiliar os alunos na apropriação de conteúdo. A pesquisa foi realizada com alunos do nono ano do ensino fundamental de uma escola pública da rede municipal de Codó-MA. A sequência didática caracterizou-se pela inserção de um experimento associado a um jogo de cartas sobre os conteúdos de $\mathrm{pH}$, acidez e basicidade. Como instrumento de coleta de dados, utilizou-se questionários semiestruturados aplicado aos alunos. Os alunos não apresentaram conceitos consistentes de significados sobre os termos "ácido e básico", bem como não souberam associar estes termos as substâncias de seu uso cotidiano. O estudo trouxe informações relevantes sobre o envolvimento e interesse dos alunos com relação ao conteúdo, mostrando que atividades desse tipo, podem contribuir para aspectos que vão além de conteúdo ministrados em sala.

Palavras-Chave: Ensino de ciências; Experimentação; ludicidade.

\section{Abstract}

This paper reports an investigation in science teaching based on a didactic sequence constructed from the association between experiments and games, with the purpose of critically analyzing the insertion of playfulness to assist students in the appropriation of content. The research was carried out with students from the ninth grade of a public school of the municipal network of Codó-MA. The didactic sequence was characterized by the insertion of an experiment associated with a card game about the contents of $\mathrm{pH}$, acidity and basicity. As a data collection instrument, semistructured questionnaires were applied to the students. The students did not present consistent concepts of meanings about the terms "acid and basic", nor did they associate these terms with the substances of their everyday use. The study provided relevant information about students' involvement and interest in content, showing that such activities can contribute to content beyond classroom content.

Keywords: Science education; Experimentation; Ludic.

\section{Resumen}

Este artículo informa sobre una investigación en la enseñanza de la ciencia basada en una secuencia didáctica construida a partir de la asociación entre experimentos y juegos, con el propósito de analizar críticamente la inserción del juego para ayudar a los estudiantes a apropiarse del contenido. La investigación se llevó a cabo con estudiantes del noveno grado de una escuela pública de la red municipal de Codó-MA. La secuencia didáctica se caracterizó por la inserción de un experimento asociado con un juego de cartas sobre los contenidos de $\mathrm{pH}$, acidez y basicidad. Como instrumento de recolección de datos, se aplicaron cuestionarios semiestructurados a los estudiantes. Los estudiantes no presentaron conceptos consistentes de significados sobre los términos "ácido y básico", ni asociaron estos términos con las sustancias de su uso diario. El estudio proporcionó información relevante sobre la participación e interés de los estudiantes en el contenido, lo que demuestra que dichas actividades pueden contribuir al contenido más allá del contenido del aula.

Palabras clave: educación científica; Experimentacíon: Juguete.

\section{AUTORES:}

SUELIR SILVA FERREIRA ${ }^{1}$

ORCID 0000-0002-1287-048X

${ }^{1}$ Universidade Federal

do Maranhão (UFMA)

CLARA VIRGÍNIA VIEIRA C.

O. MARQUES

0000-0002-1550-2252

${ }^{2}$ Universidade Federal do Maranhão (UFMA)

PAULO ROBERTO BRASIL DE OLIVERA MARQUES ${ }^{3}$

ORCID 0000-0002-2860-0417

3 Universidade Federal do Maranhão (UFMA)

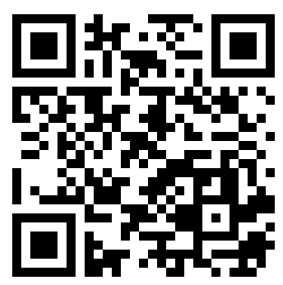

Para citar este artigo:

FERREIRA, S. S.; MARQUES, C. V. V. C. O. M.; MARQUES, P. R. B. O. Implementação de Sequência Didática Experimental na Perspectiva da Ludicidade: Construindo saberes sobre $\mathrm{PH}$. Revista Eletrônica Ludus Scientiae, Foz do Iguaçu, v. 03, n. 01, p. 20-32, jan./jul. 2019. 


\section{INTRODUÇÃO}

O Ensino de Ciências no Brasil vem passando por mudanças nas últimas décadas, no que diz respeito à legislação educacional orientadora. Apesar das reformas efetuadas no final da década de 1990, ainda não foi possível superar a postura tradicional que a escola normalmente adota, em relação a proposições de metodologias de ensino, distanciando, portanto, o cotidiano do aprendiz na aquisição de conhecimentos que o Ensino de Ciências se responsabiliza, tendo como principal consequência, a falta de interesse do aluno pela área (BRASIL, 1997). Segundo Macedo (2004), ao ensinar ciências o professor deveria criar condições em que os estudantes desenvolvessem uma postura crítica em relação aos conhecimentos científicos e tecnológicos, por meio da viabilização de atividades desafiadoras para o pensamento e relacionando-as aos comportamentos do ser humano diante da natureza. Nesse sentido, torna-se necessária a proposição de ações nas aulas de ciência que levem ao pensar crítico e criativo visando ao fomento de habilidades sociais que serão necessárias na vida dos sujeitos (WEISSMANN, 1998).

É nesse contexto que a atividade experimental entra em cena apresentando-se como suporte crítico no Ensino de Ciências, podendo propiciar aos estudantes momentos de registros sistemáticos, promoção de discussões com os colegas, reflexões, levantamentos e avaliação de hipóteses e suas possíveis explicações. Discutir com o professor todas as etapas de um experimento cria naturalmente um ambiente de desenvolvimento e de apropriação de linguagem científica, sendo, portanto, papel do professor fomentar essas atitudes, quebrando a imposição de explicações prontas sem problematizar as observações dos alunos (ZABEL; SIPLE, 2013). Giordan (1999) afirma que experimentos normalmente despertam curiosidade e motivam os alunos a quererem saber mais sobre diversos assuntos das ciências, levando-os a problematizações de situações com levantamento de hipóteses discursivas.

Assim, a experimentação, embora sendo um recurso ainda pouco utilizado pelos docentes de ciências naturais em sala de aula, tem mostrado caráter lúdico e pode facilitar a discussão de conceitos e fenômenos decorrentes das ciências naturais presentes no cotidiano dos alunos (FRANCISCO Jr.; SANTOS, 2011; LOBO, 2012). Oliveira (2009) afirma que quando um aluno se dedica a uma atividade experimental a sua postura emocional é similar ao envolvimento com um jogo.

Entendendo que dinâmicas lúdicas auxiliam na busca de melhores resultados por parte de educadores interessados em promover mudanças no processo de ensino e aprendizagem, contribuindo para uma aula mais dinamizada, defende-se como fundamental que o professor, em sua formação, tenha acesso às formas e meios de aplicação de eventuais experimentos lúdicos em sala de aula/laboratório, colocando em prática o saber produzido por essa área de pesquisa mesmo tendo ciência da carência de condições para trabalharem a experimentação, como por exemplo, o número de alunos por turma, falta de infraestrutura e principalmente a carga horária reduzida para as atividades experimentais (GADÉIA; DORN, 2011).

A abrangência do tema sobre experiências lúdicas vem sendo divulgada em artigos científicos, pelo fato de evidenciar a possibilidade de alcançar uma aprendizagem mais significativa e com resultados positivos. Dessa forma, a escolha de atividades para construção de conhecimento através de jogos didáticos não deve ser entendida como preenchimento de lacunas de horários ou para tornar o ensino dessas disciplinas mais divertidas e sim, como algo que pode levar os alunos a terem a decisão de aprender com prazer (CUNHA, 2012).

Mas, de uma maneira geral, as propostas de experimentação como processo metodológico de ensino-aprendizagem têm sido pouco exploradas, sendo os experimentos aplicados de forma demonstrativa, configurando assim um processo de observação distante, na maioria das vezes. Segundo a literatura, as atividades experimentais quando ocorrem nas escolas, na visão de vários autores, apresentam-se sob a ótica de quatro classificações, a saber: (i) demonstrativa, (ii) ilustrativa, 
(iii) descritiva e (iv) investigativa (GALIAZZI; GONSALVES, 2004). Pontua-se que as propostas de experimentação investigativas trazidas em livros didáticos normalmente são apresentadas de forma 'roteirizadas' e não possibilitam uma liberdade de manuseio pelos alunos, dificultando assim o encaminhamento de competências por meio das várias formas de aplicação em sala de aula (OLIVEIRA, 2009).

A partir do que foi apresentado e da premissa de ganhos significativos ao se utilizar a experimentação de forma lúdica no Ensino de Ciências, o presente trabalho é um recorte de uma pesquisa realizada no Ensino Fundamental onde buscou-se implementar analiticamente atividades experimentais de cunho lúdico para criar condições de verificação da seguinte questão de pesquisa: As práticas de experimentação associadas a ludicidade podem revelar quais elementos no processo de apropriação de conteúdo? A ludicidade inserida nas práticas de experimentação pode ser fator diferencial no processo de ensino-aprendizagem?

\section{PERCURSO METODOLÓGICO}

A proposta metodológica foi pautada nos princípios da pesquisa qualitativa, tendo desenho metodológico iniciado por levantamento bibliográfico sobre experimentação e ludicidade, seguido da escolha e adaptação de um experimento que foi previamente testado, validado e posteriormente aplicado em uma escola pública da cidade de Codó-MA, a partir de uma sequência didática que aliou experimentação e ludicidade. Essa aplicação foi avaliada através de questionários destinados a uma amostragem de alunos e os dados foram organizados em redes sistêmicas para análise de conteúdo.

Pontua-se que o levantamento bibliográfico foi efetuado em sites e revistas acadêmicas nas bases de dados e portais específicos de publicação científica acadêmica dentro do período de janeiro a dezembro de 2017. Dessa forma, foram consultadas as seguintes revistas: Química Nova, Química Nova na Escola, Revista Virtual em Química, Revista Ensaio e Revista Brasileira de Pesquisa em Educação em Ciências. Dessa classificação foram selecionados cinco artigos que apresentavam ou poderiam ser relacionados às propostas de experimentação, para definição da adaptação do experimento a ser apresentado na sequência didática, de acordo com os seguintes critérios: materiais de fácil acesso, tempo curto de execução, possibilidade de uso de materiais alternativos e possibilidade de contextualização.

O experimento foi então definido e montado, sendo construído um roteiro específico. $\mathrm{O}$ experimento foi então testado no laboratório de química da Universidade Federal do Maranhão, do Campus VII, Codó-MA, sendo efetuadas posteriormente as devidas correções a adaptações finais que alcançassem o público a que se destina (escola de Ensino Fundamental).

Foi efetuada também uma análise no livro didático de ciências utilizado pela escola, a respeito do conteúdo relativo à prática que seria aplicada, objetivando observar como o livro discute o conteúdo. A sequência didática foi pensada a partir de uma proposta de experimentação conectandoa a um jogo adaptado de propostas encontradas na internet.

A experimentação foi aplicada aos alunos, em sala de aula, com a supervisão do professor de ciências da escola. Em seguida foi aplicado um questionário aberto. A segunda etapa foi a aplicação do jogo, seguida de coleta de dados a partir de um questionário semiestruturado. Os dados foram então analisados na perspectiva de análise de conteúdo buscando identificar os significados construídos e revelados nas respostas dos alunos (BARDIN, 2016; MARQUES, 2016).

\section{RESULTADOS E DISCUSSÕES}

\section{Levantamento bibliográfico}


Foram encontrados 78 artigos, sendo a sua maioria publicada na revista Química Nova na Escola (33), tendo 17 artigos publicados na Revista Brasileira de Pesquisa em Educação em Ciências, 15 artigos na Química Nova, 6 artigos na Revista Virtual em Química, 7 artigos na revista Ensaio. O gráfico da Figura 1 apresenta as porcentagens para a classificação dos artigos.

- Vídeos

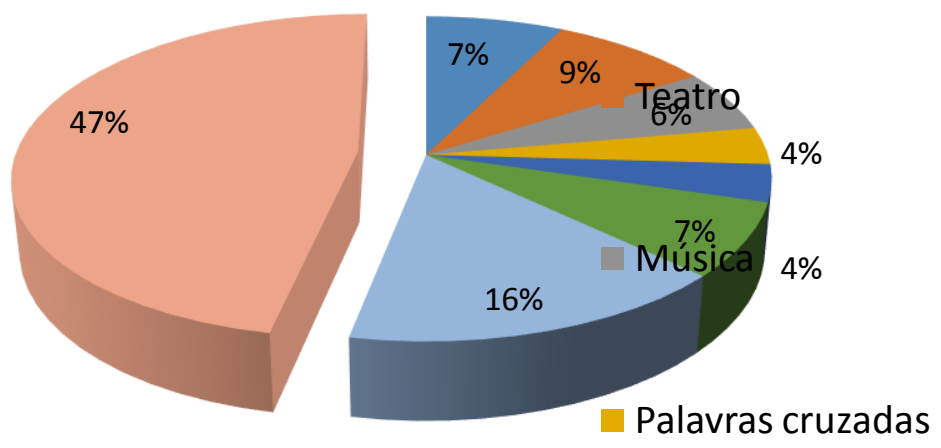

Figura 1: Gráfico de dados percentuais do levantamento bibliográfico efetuado sobre ludicidade e experimentação.

Observou-se que a maioria dos artigos traz como foco direto uma proposta de experimentação com material alternativo, seguida de atividades formais de laboratório, não sendo a ludicidade o foco principal do trabalho. Nesse contexto, identificou-se como atividades lúdicas os que envolviam: música, teatro, dança, fotonovelas, uso de TIC e palavras-cruzadas/quadrinhos. Em sua maioria, os artigos apresentaram experimentação investigativa ou demonstrativa, onde o professor é o técnico/sujeito principal e o aluno, observa, anota e classifica. Os artigos apresentam estudos aplicados a alunos do Ensino Fundamental segunda etapa e ao Ensino Médio, tendo como principais intuitos o de promover a fixação e maior compreensão dos conteúdos de difícil compreensão com relação às disciplinas de química, física e biologia.

O teatro como área de conhecimento pode auxiliar em uma série de dificuldades teóricas e práticas em sala de aula. Usando o teatro como meio alternativo para o trabalho em grupo, pode-se trabalhar a capacidade de ver e ouvir, dos alunos com relação a aquisição de conteúdo. Segundo Messeder Neto, Pinheiro e Roque (2013), o uso das improvisações teatrais é uma alternativa lúdica e não apresentam apenas o poder de motivar os estudantes, mas também, levantar concepções prévias e posteriores ao ensino. O emprego de músicas como ferramentas de ensino também abre possibilidades para o debate entre ciência e arte, podendo transformar a sala de aula em um espaço dialógico com influências culturais.

Para Kundlatsch e Silveira (2018), o desenvolvimento de atividades como palavras cruzadas e leitura de quadrinhos pode garantir a maior participação e maior envolvimento do aluno em qualquer que seja a atividade desenvolvida, pelo caráter de novidade e perspectiva de sair da passividade a que normalmente são submetidos, para agir e tomar suas decisões com caráter livre e espontâneo.

As fotonovelas são forma de arte sequencial, que observam texto e imagens, com o objetivo de narrar histórias dos mais variados estilos. Nessa perspectiva, podem ser abordados temas da atualidade ou científicos, como os denominados temas químico-sociais. Esse método de ensino é desenvolvido 
em sala de aula e é uma estratégia de ensino de grande valia para instigar o aluno no caminho que conduz à consolidação do hábito e prazer da leitura no processo de construção do conhecimento, pois instiga a reflexão, a pesquisa e a criação, discutindo ideias e elaborando hipóteses (FERREIRA; SILVA, 2011).

Segundo Parisoto e Hilger (2016), recursos computacionais são alternativas que podem ampliar os conceitos químicos, físicos e matemático, além de criar pontes cognitivas para o conhecimento. Dessa forma, os experimentos em química, por exemplo, podem explorar tópicos como geometria molecular, ligações químicas e polaridade das moléculas, que são propostas em acordo com as tendências de uso de TIC para o Ensino de Ciências. Assim, as propostas de ludicidade e experimentação revisadas se apresentaram variadas, o que enriquece a produção sobre a relação entre o fazer da ciência e o lúdico, em um mesmo contexto, o que colabora com o Ensino de Ciências.

\section{Seleção, teste e validação do experimento}

A partir dos dados do levantamento foram selecionados artigos relacionados à experimentação com bases em testes de $\mathrm{pH}$. O valor de $\mathrm{pH}$ serve como parâmetro utilizado para definição de grau de acidez e basicidade de uma solução, podendo ser facilmente encontrado em rótulos de garrafas de água mineral, por exemplo, ou nas contas de água. A partir dos artigos foi proposta uma experimentação na sequência didática, que teve por base um teste de $\mathrm{pH}$ a partir de uso de repolho roxo como indicador, combinado a materiais caseiros como soluções a serem testadas. As mudanças de coloração nas práticas de $\mathrm{pH}$, bem como a manipulação de materiais alternativos para outros fins, apresentam caráter de ludicidade, visto que o aluno pode associar de forma visual, a partir de mudança de cor, conteúdos distintos, podendo trabalhar e desenvolver conceitos abstratos. A associação de objetos cotidianos a ações prazerosas na construção de experimentos para a escola também traz a possibilidade de ludicidade (OLIVEIRA, 2009).

Para o procedimento de teste, as substâncias de uso cotidiano que foram utilizadas no experimento foram: água, leite, açúcar, detergente, água sanitária, limão, álcool, vinagre e bicarbonato de sódio. Logo após os testes, o experimento foi validado e os alunos não tiveram dúvidas que pudessem sugerir alterações no roteiro ou percurso do experimento, que apresentou duração de dez minutos. A Figura 2 apresenta uma foto da atividade de validação.

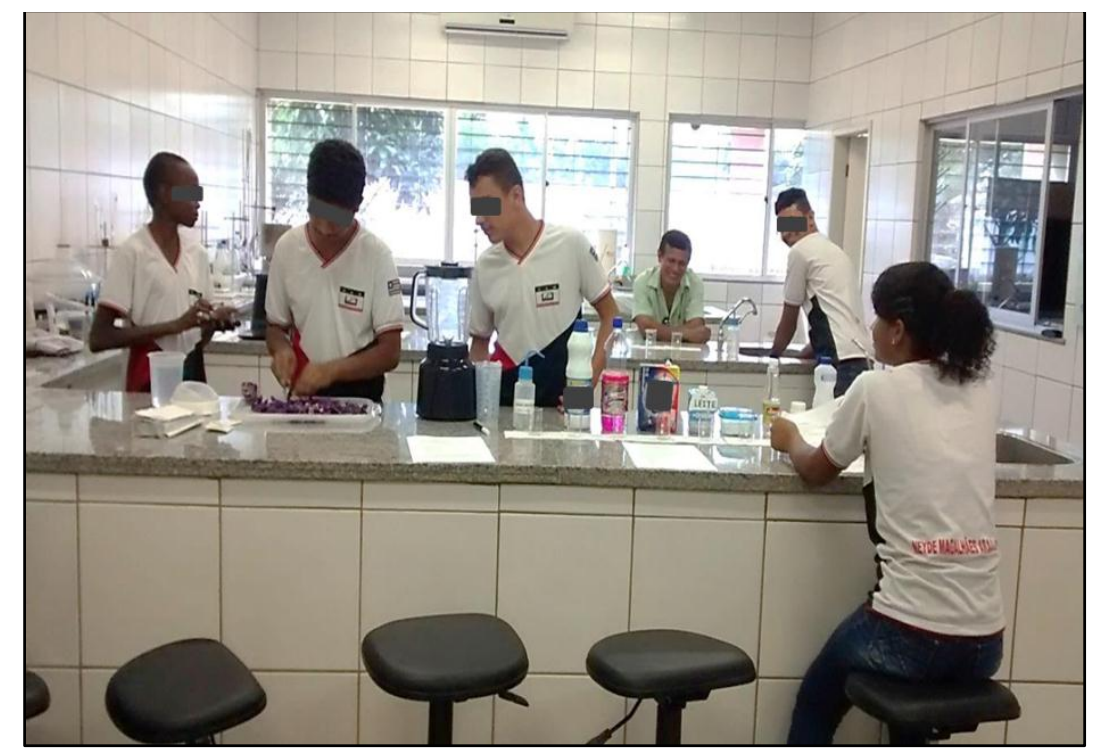

Figura 2: Etapa de validação do experimento efetuada no laboratório de química. Fonte: Autora. 


\section{Caracterização da escola e dos sujeitos da pesquisa}

A escolha da escola para aplicação da sequência didática foi motivada por parcerias já existentes entre escola-universidade por meio de projetos de ensino/extensão e de atividades de estágio supervisionado. A escola funciona nos turnos matutino, vespertino e noturno, ofertando ensino fundamental e etapas de ensino de jovens e adultos. Apresenta boa infraestrutura, com destaque para o laboratório de informática e a biblioteca, sendo que a escola também disponibiliza de equipamentos como computadores para alunos, televisões nas salas de aula e aparelho de DVD. Até o momento da pesquisa, a escola trabalhava com 27 professores, sendo $90 \%$ deles na condição de efetivos, atuantes no turno matutino e vespertino. A turma selecionada para a aplicação da experimentação foi a do nono ano, visto que o conteúdo relativo à acidez, basicidade e $\mathrm{pH}$ é melhor discutido nos conteúdos de química desta etapa do fundamental. Assim, os sujeitos da pesquisa foram um total de 32 alunos, com faixa etária entre 14 e 17 anos.

\section{Análise do livro didático de ciências}

Foi verificado que o livro de ciências utilizado pela escola, no nono ano, foi o da coleção Companhia das Ciências, Editora Saraiva, volume 9, dos autores Usberco, Manuel, Schechitmann, Ferrer e Velloso (2015). O livro se subdivide em três unidades, sendo: Unidade 1: fundamentos de química e física, Unidade 2: Introdução ao estudo da química e, Unidade 3: Introdução ao estudo da física. Os conteúdos relativos aos conceitos correlacionados ao $\mathrm{pH}$ estão descritos no capítulo 12 , intitulado "Funções Inorgânicas: ácidos e bases" (pg. 28).

Em uma avaliação geral, o capítulo se apresenta bem estruturado, com gravuras, fotos e desenhos que representam o processo de acidez-basicidade de forma contextualizada, relacionando conceitos, características, bem como precauções em casos específicos de risco a saúde humana. São citados produtos cotidianos como o vinagre, limão, tomate, detergente, alvejante, entre outros. Apresenta uma breve citação relacionada à história da ciência e faz referência a testes alternativos de $\mathrm{pH}$, como o do repolho roxo. A ideia de $\mathrm{pH}$ é bem-apresentada como medida de caráter ácido/básico, bem como graus de acidez e basicidade.

A partir da análise, verificou-se que o livro aborda o tema de forma apropriada e que pode ser relacionado com o cotidiano do aluno, sem imprimir conceitos mais complexos sobre o parâmetro $\mathrm{pH}$, sendo um ótimo instrumento para trabalhar o conteúdo sobre acidez e basicidade. A Figura 3 apresenta um recorte do livro apresentando o repolho roxo como indicador de $\mathrm{pH}$.

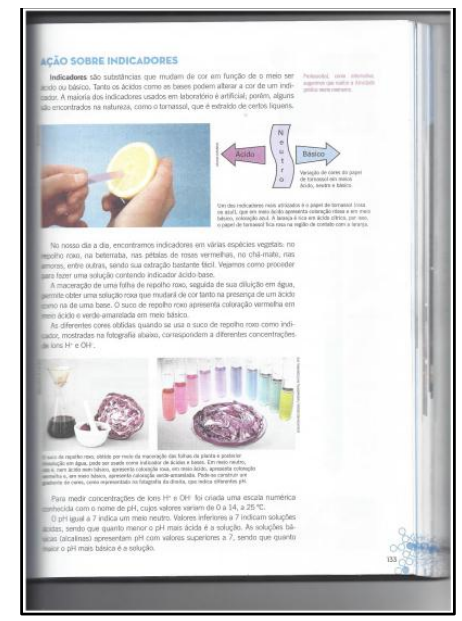


Figura 3: Representação de testes de $\mathrm{pH}$ no livro de ciências utilizado no nono ano da escola pública (USBERCO, et al. 2015).

\section{Aplicação da sequência didática}

\section{Experimentação}

Como citado anteriormente, a sequência didática foi pensada para ser aplicada em dois momentos, sendo: experimentação (i) seguida de aplicação de um jogo (ii). A etapa da experimentação foi preparada para ser efetuada na escola, sob a supervisão do professor de ciências da turma selecionada. Pontua-se que primeiramente implementou-se um questionário diagnóstico, objetivando avaliar o grau de conhecimento dos alunos sobre o tema. A aplicação da atividade experimental ocorreu de forma adaptada às condições do ambiente escolar, tendo, os alunos, atuado de forma participativa, ou seja, todos puderam se expressar de forma espontânea, apresentado comentários, dúvidas e curiosidades a respeito do tema trabalhado, que recebeu a denominação de "Determinação de $\mathrm{pH}$ e sua utilidade para a vida”. A Figura 4 apresenta foto da atividade de experimentação.

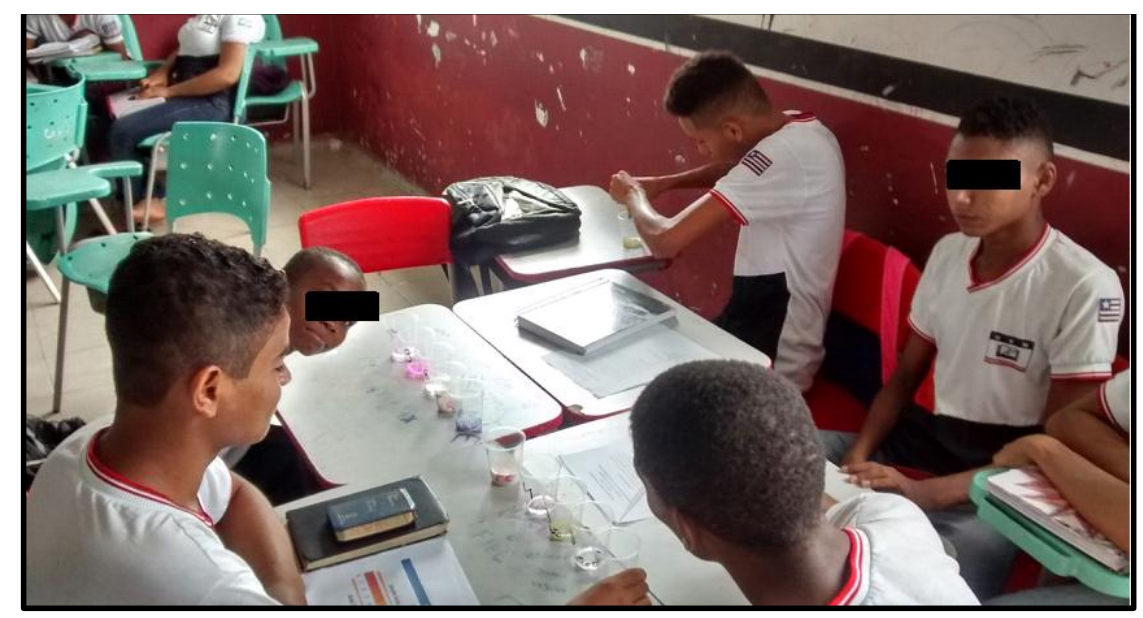

Figura 4: Atividade experimental sobre escala de $\mathrm{pH}$ realizada por alunos do nono ano da escola em atividades do estudo. Fonte: Autora.

Após a atividade experimental foi aplicado o questionário investigativo aos 32 alunos. Dentre eles, 26 alunos conseguiram classificar cada produto corretamente dentro do que lhe foi apresentado e 6 alunos não conseguiram exemplificar com coesão. Chamou a atenção o fato de que o conceito de acidez está mais claro nas explicações dos alunos do que o de basicidade ou de neutralidade. Quando se discutiu o conceito de $\mathrm{pH}$, os alunos ainda apresentam dúvidas nas definições dos parâmetros: 23 alunos descreveram uso do $\mathrm{pH}$ e não o conceito em si, 5 confundiram conceitos de indicador com conceito de $\mathrm{pH}, 4$ não conseguiram definir $\mathrm{pH}$, e 9 alunos destacaram somente o lado prazeroso da atividade experimental, sem focar nenhum conceito. O Quadro 1 apresenta alguns recortes da escrita dos alunos no questionário. 
Quadro 1: Recortes das escritas dos alunos no questionário investigativo aplicado após a experimentação. Questão conceitual.

\begin{tabular}{cc}
\hline QUESTIONAMENTO & RECORTE DAS RESPOSTAS \\
\hline & "Que o pH é para medir se os alimentos ou objetos de limpeza são \\
ácidos ou não" A3 & "Que se misturar limão e bicarbonato de sódio, espuma” A32 \\
Comente sobre o & "Eu aprendi que o pH é uma sigla que é potencial hidrogeniônico, \\
experimento proposto? & são usadas também a solução neutra, básica e ácida” A29 \\
"Que o suco de repolho roxo é o pH, ele muda as cores" A23 \\
"Que misturar substâncias diferentes obtemos cores diferentes como \\
também reações diferentes" A5
\end{tabular}

A = aluno, № = questionário.

Quando solicitado aos alunos que citassem e classificassem substâncias do seu cotidiano como ácidas ou básicas, a maioria (78\%) não conseguiu ir além daquelas usadas no experimento proposto (limão, vinagre, bicarbonato de sódio e sabão), e ainda assim, 7 alunos (22\%) não conseguiram descrever corretamente os produtos, misturando informações sobre alimentos ácidos, básicos e neutros. Merece destaque ainda a citação de um aluno em que colocou a química como algo ruim a partir do caráter ácido dos alimentos, indicando acidez como "algo prejudicial para a alimentação".

Esses dados revelam os prejuízos de aulas tradicionais que não prezam por contextualização do conteúdo relativo à acidez e basicidade, onde o aluno trabalha o conteúdo, mas não o localiza no seu dia a dia, refletindo minimamente a escassez da alfabetização científica que deveriam ocorrer nas aulas de ciências, onde os conteúdos deixariam de ser livrescos, prontos e finalizados, sem função na vida do aluno (CHASSOT, 2003). Assim, em uma avaliação geral, observou-se que os alunos, em sua maioria, apenas repetiram conceitos apresentados na experimentação, bem como processos e substâncias utilizadas (Quadro 2).

Quadro 2: Recortes das escritas dos alunos no questionário investigativo aplicado após a experimentação. Questão aplicada.

QUESTIONAMENTO

Substâncias ácidas do seu dia a dia

\section{RECORTE DAS RESPOSTAS}

"Limão e vinagre" A1

"Café, álcool e vinagre" A5

“Água sanitária e vários outros” A12

\section{Substâncias básicas do seu dia a dia}

"Bicarbonato de sódio e sabão" A24

"Álcool, leite, detergente e água” A9

"Vinagre, açúcar e vários outros" A7

$\mathrm{A}=$ aluno, № = questionário.

Mota e Cleophas (2014), aplicando experimentação com extratos da planta Pterodon abruptus (Moric.) Benth como indicador natural, para um grupo de discentes em um curso de formação em ciências naturais, evidenciaram que poucos alunos conheciam a proposta de indicadores naturais.

Segundo Arroio et al. (2006), a experimentação possui um caráter lúdico quando se dá a liberdade aos alunos de se expressarem, possibilitando que os mesmos criem hipóteses e ideias. 
Percebe-se empolgação e empenho na realização da atividade proposta e, por não ser uma atividade rotineira em sala, gera ansiedade e euforia por parte dos alunos em sua execução.

Com bases nesses dados pode se perceber a prática experimental como algo que pode auxiliar o professor na sua práxis docente, aliada à aula teórica, onde conceitos e exemplificações do dia a dia podem ser o diferencial na aprendizagem dos alunos, cabendo ao professor a difícil tarefa de educar por meio de atividades expressivas, contextualizadas e que promovam alfabetização científica.

Nessa etapa inicial do trabalho, o caráter lúdico da prática, definido a partir das mudanças de cores no sistema de experimentação foi pontuado e destacado pelos alunos, porém, não foi delineador de produção dos conceitos químicos desejados.

\section{Atividade lúdica: jogo de cartas}

É importante ressaltar que a partir da análise do questionário aplicado na etapa da experimentação foi pensando e montado o jogo, denominado "jogo de cartas". A proposta foi pensada para a necessidade do aprimoramento de conceitos verificados no primeiro momento da sequência didática uma vez que foi detectado um baixo nível de apropriação pelos alunos. Dessa forma, primouse por pontuar os conteúdos de: acidez, basicidade, $\mathrm{pH}$, escala de $\mathrm{pH}$, substâncias ácidas e básicas, indicador de $\mathrm{pH}$, exemplos e advertências.

O jogo teve o formado "perguntas e repostas" onde as perguntas elaboradas faziam alusão as proposições colocadas na etapa da experimentação. Foram formados dois grupos, onde cada grupo teve o direito a uma pergunta por vez, sendo que, ao responder deveriam se remeter a momentos da experimentação, e quando respondidas corretamente, o grupo de alunos prosseguia para a pergunta seguinte, e caso não respondesse corretamente, a pergunta seria direcionada para outro grupo de alunos. Foram feitas 10 perguntas para cada grupo, em um total de 18 perguntas lançadas. Conforme os acertos, os pontos eram marcados.

Os próprios componentes do grupo indicaram a sequência de alunos (representantes de grupo) que responderiam às questões, sendo que um mesmo componente não poderia responder mais de duas vezes. O grupo que conseguisse mais pontos, seria então considerado o vencedor da rodada, com direito a premiação. Caso nenhum grupo acertasse a pergunta, o mediador apresentava a resposta correta e promovia discussão a respeito.

Dessa forma, a dinâmica do jogo foi aplicada na sala de aula, tendo 24 participantes (alunos presentes), com supervisão do professor de ciências, tendo duração de $45 \mathrm{~min}$. A Figura 5 apresenta uma etapa da validação do jogo.

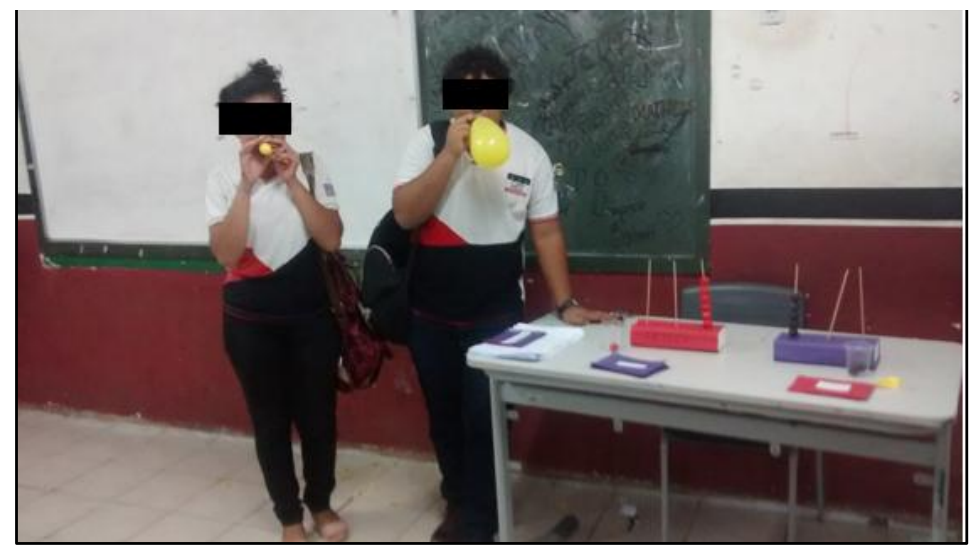

Figura 5: Validação do jogo de cartas sobre escala de pH com base na experimentação aplicada aos alunos de nono ano. Fonte: Autora. 
Primeiramente, as regras do jogo foram explicadas, sendo posteriormente definidos os dois grupos (grupo ácido e grupo base). Em seguida foram escolhidos sete representantes para cada grupo, onde teriam que estourar um balão que serviria de sinalizador para o início das perguntas. Cada pergunta foi direcionada ao mediador, que por sua vez, repassava a pergunta em voz alta para todos os colegas, inclusive para o grupo indicado para respondê-la. Os alunos tinham cinco minutos para elaborar a resposta (foi permitido uso de livro didático como material de consulta). Após todas as perguntas, finalizou-se o jogo, definindo o grupo vencedor.

Após a implementação do jogo foi aplicado outro questionário para análise de dimensões que validassem o jogo criado e proposto. Utilizou-se para essa etapa adaptação de categorias previstas em Souza, Pires e Linhares (2015), detalhadas a seguir: perfil do jogador, atitude perante o jogo, tática de jogo, aprendizado e conceitos. O questionário foi aplicado aos 24 alunos participantes da atividade lúdica.

Da análise evidenciou-se que $58 \%$ dos jogadores foram do sexo feminino e $42 \%$ masculino. $96 \%$ disseram gostar de jogos, sendo que $50 \%$ responderam ter hábito de jogar, citando como exemplo: gincana, futebol e basquetebol, atividades da própria escola. Dentre atividades extraescola que fazem alusão a ludicidade foram destacadas: videogame, jogo da garrafa, dama e jogo da memória. Quando perguntados sobre a personagem percebida e assumida em um jogo, $38 \%$ declararam postura de liderança, $25 \%$ assumiriam papel de mediador de tarefas e $37 \%$ não souberam dizer que postura assumiriam em um jogo.

Com relação ao sentimento quando ganha um jogo, os alunos/alunas declararam, em sua maioria (92 \%), que ficam alegres/felizes, $4 \%$ ficam orgulhosos e $4 \%$ se sentem campeões. Assim, percebe-se a partir das respostas, uma aproximação com felicidade, orgulho e status perante os outros alunos.

Já com relação ao sentimento de perda em um jogo, $67 \%$ se declararam que costumam ficar tristes, $8 \%$, ficam raivosos, $8 \%$ se sentem campeões, mesmo perdendo, pois participaram do jogo e aprenderam algo novo e $18 \%$ acham normal ou se conformam. $71 \%$ dos alunos declararam que retornam a jogar, mesmo após perder uma partida, tendo com o intuito, ganhar ou como forma de esforço pessoal.

Com relação às estratégias, $33 \%$ não possuem estratégias específicas para jogar, $21 \%$ gostam de trabalhar em grupo, $17 \%$ acreditam que os conteúdos bem estudados podem levar a jogar de forma mais preparada para ganhar, $17 \%$ focaram na atenção e dedicação e $8 \%$ destacaram o respeito às regras.

Sobre o jogo aplicado em sala de aula com o tema $\mathrm{pH}$, todos descreveram o momento como algo bom/ótimo, e que puderem aprender algo de novo. Sobre essa aprendizagem, destacaram o saber ganhar e perder $21 \%$, já $13 \%$ responderam que aprenderam a respeitar regras, $17 \%$, trabalhar em equipe. Segundo Oliveira (2009), as atividades de experimentação investigativas são necessárias para compreensão de fenômenos, além de exercerem sobre os alunos um dado fascínio que os desafiam a desvendá-los, características também presentes nos jogos.

Nessa mesma linha, vários autores defendem jogos e atividades lúdicas como instrumentos que facilitam tanto o processo de ensino como o de aprendizagem, por proporcionarem interações ativas entre docentes e discentes. Portanto, tanto o jogo como a experimentação têm caráter de ludicidade quando apresentam características tais como: presença de regras, delimitação de espaço, tempo de ação, voluntariedade, personificação e cultura (LOPES, 2011; KISHIMOTO 2011; RAU 2007).

Para Kishimoto (2011) a associação de atividades lúdicas para fins educativos têm grade relevância social, pois contribui diretamente para o desenvolvimento do aprendiz em vários aspectos 
necessários para o saber viver em sociedade, tais como: desenvolvimento corporal, estímula a vida psíquica e a inteligência.

Em relação aos conceitos de $\mathrm{pH}$ revelou-se que $13 \%$ dos alunos continuaram na base de descrição de conceitos fragmentos sobre o tema de acidez e basicidade. Destaca-se ainda que $42 \%$ apresentaram respostas evasivas ou genéricas. Esse resultado aponta para uma necessária preocupação em relação ao processo de ensino, uma vez que, embora as atividades propostas motivem os alunos a participarem efetivamente das atividades, mas o nível de intimidade deles com o saber científico ainda é raso, levando, obviamente a dificuldades na construção de argumentos na ciência. A Tabela 3 apresenta recortes das repostas dos alunos.

Quadro 3: Recortes das respostas dos alunos ao questionário investigativo relativo a ludicidade e experimentação.

\begin{tabular}{lc}
\hline \multicolumn{1}{c}{ QUESTÃO } & RECORTE DAS RESPOSTAS \\
\hline Como você se sente quando ganha o jogo? & "Feliz e muito alegre" A1 \\
"Orgulhoso" A4
\end{tabular}

$\mathrm{A}=$ aluno, № = questionário.

Essa situação pode estar atrelada ao fato da pouca existência de atividades de ensino que incentivem o processo de argumentar criticamente. Segundo Henao e Stipcich (2008) o saber argumentar revela o nível de aprendizado dos alunos, o que será possível se as suas habilidades comunicativas forem trabalhadas em consonância com as habilidades inerentes ao processo de construção dos saberes científicos.

\section{CONSIDERAÇÕES E CONCLUSÃO}

A partir do levantamento bibliográfico pode-se evidenciar que a maioria dos trabalhos sobre experimentação no Ensino de Ciências disponibilizados em revistas acadêmicas direcionam-se para a área de química, pontuando-se na perspectiva de implementação de práticas experimentais com material alternativo. A presente proposta de experimentação selecionada, validada e aplicada em uma sequência didática apresentada nesse artigo caracterizou-se como bem relevante e apropriada para o ensino do conteúdo $\mathrm{pH}$, visto que mostrou-se com potencial para levar os alunos a refletirem sobre o assunto já ministrado em sala de aula e de subsidiar compreensões ainda não apropriadas, sendo assim, um caminho diferenciado que levantou a possibilidade de trabalhar conceitos de ciências sob a ótica de novas perspectivas, principalmente por privilegiar a forma de ensino contextualizado, além de serem elaboradas a partir de manuseio como materiais de baixo custo e presente no cotidiano da escola.

Os questionários investigativos aplicados aos alunos após a experimentação evidenciaram que os mesmos apresentam conceitos mal estruturados sobre $\mathrm{pH}$, acidez e basicidade, pontuando principalmente que esses termos são normalmente confundidos e não percebidos no cotidiano dos alunos. Esse é um problema real quando se pesa em aprendizagem significativa. Porém, ressalta-se que outras habilidades podem ser desenvolvidas nos alunos quando se trabalha de forma lúdica, que não necessariamente a aquisição de conhecimentos científicos, mas de elementos que podem levar a facilitação do desenvolvimento de postura científica, como por exemplo, o estabelecimento de 
estratégias para alcançar êxitos nos resultados alcançados e terem a consciência na necessidade de obter conhecimentos teóricos para evoluir nos jogos e vencerem as etapas propostas.

Assim, entende-se que a inserção de um jogo em uma sequência didática após o trabalho experimental é propositiva em um planejamento didático, pois possibilita o surgimento de um espírito de competição educativa. Considera-se, portanto, que atividades lúdicas em conexão com atividades de ensino, como a experimentação por exemplo, podem se apresentar como forma de estabelecimentos de elos entre os objetivos de ensino e de aprendizagem, uma vez que além de permitir a construção de um ambiente acolhedor e dinâmico, amplia a possibilidade de aprendizagem, transcendendo os muros da prática tradicional normalmente implementada nas aulas de ciências. É necessário que as escolas e os professores estabeleçam relações rotineiras entre a atividade lúdica e o aprendizado dos estudantes, compreendendo que é possível aprender pela promoção de atividades que divirtam.

Sob esse aspecto, considera-se que a sequência didática aplicada pode ser utilizada como instrumento de fortalecimento de conteúdos relativos ao Ensino de Ciências, visto que experimentação e ludicidade podem ser associadas como atividades em ambientes não formais a partir de situações-problema específicas.

\section{REFERÊNCIAS}

ARROIO, A.; HONÓRIO, K. M.; WEBER, K. C.; HOMEN-DE-MELLO, P.; GAMBARDELLA, M. T. P.; SILVA, A. B. F. O show da química: motivando o interesse científico. Química Nova, v. 29, n. 1, p.173-178, jan. 2006.

BARDIN, L. Análise de Conteúdo. 1. ed. São Paulo: Edições 70, 2016, 280 p.

BRASIL. Secretaria de Educação Fundamental. Parâmetros Curriculares Nacionais: ciências naturais/Secretaria de Educação Fundamental. - Brasília: MEC/SEF, 1998. 136p.

CHASSOT, A. Alfabetização científica: uma possibilidade para a inclusão social. Revista Brasileira de Educação. n. 22, p.89-100, jan-abr. 2003.

CUNHA, M. B. Jogos no ensino de química: considerações teóricas para sua utilização em sala de aula. Química Nova na Escola, v. 34, n. 2, p. 92-98, maio. 2012.

FERREIRA, W. M.; SILVA, A. C. T. As fotonovelas no ensino de química. Química Nova na Escola. v. 33, n 1, p.25-31, fev. 2011.

FRANCISCO Jr.; W. E.; SANTOS R. I. Experimentação mediante vídeos: concepções de licenciandos sobre possibilidades e limitações para a aplicação em aulas de química. Revista Brasileira de Ensino de Ciências e Tecnologia, v. 4, n. 2, p.105-125, maio-ago. 2011.

GADÉIA, S. J. S.; DORN, R. C. Alfabetização científica: pensando na aprendizagem de ciências nas séries iniciais através de atividades experimentais. Experiências em Ensino de Ciências, v. 6, n. 1, p. 113-131, mar-jun. 2011.

GALIAZZI, M. C.; GONÇALVES, F. P. A natureza pedagógica da experimentação: uma pesquisa na licenciatura em química. Química Nova, v. 27, n. 2, p. 326-331, ago. 2004.

GIORDAN, M. O papel da experimentação no ensino de ciências. Química Nova na Escola, n. 10, p. 43-49, nov. 1999 .

HENAO, B. L.; STIPCICH, M. S. Educación en ciências y argumentación: la perspectiva de toulmin como posible respuestas as demandas y desafios contemporâneos para la ensenaza de las ciências experimentales. Revista Eletrônica de Ensenanza de las Ciências, v.7, n.1, p 47-62, 2008.

KISHIMOTO, T. M. Jogo, brinquedo, brincadeira e a Educação. 14 ed. São Paulo: Cortez, 2011, 208p. 
KUNDLATSCH, A.; SILVEIRA, C. A temática soluções nas histórias em quadrinhos: análise de uma atividade desenvolvida com estudantes do ensino médio. Revista de Ensino de Ciências e Matemática, v.9, n.5, p. 3655, dez. 2018.

LOBO, S. F. O trabalho experimental no ensino de química. Química Nova, v. 35, n. 2, p.430-434, set. 2012.

LOPES, M. G. Jogos na educação: criar, fazer, jogar. 7 ed. São Paulo: Cortez, 2011, 16op.

MACEDO, E. Ciência, tecnologia e desenvolvimento: uma visão cultural do currículo de ciências. In: LOPES, A. C.; MACEDO, E. (Orgs.). Currículo de ciências em debate. Campinas: Papirus, 2004, p. 119-153.

MARQUES, C. V. V. C. O. M. Formação inicial na docência em química: reformulações e realidade. São Luís: EDUFMA, 2016, 317p.

MESSEDER NETO, H. S.; PINHEIRO; B. C. S.; ROQUE, N. F. Improvisações teatrais no ensino de química: interface entre teatro e ciência na sala de aula. Química Nova na Escola, v. 35, n. 2, p. 100-106, maio. 2013.

MOTA, T. C.; CLEOPHAS, M. G. Proposta de ensino de química utilizando a planta Pterodon abruptus (Moric) Benth. Como indicador natural de pH. Revista Virtual de Química. v. 6, n. 5, p. 1353-1369, set. 2014.

OLIVEIRA, N. Atividades de experimentação investigativa lúdicas no ensino de química: um estudo de caso. 2009. Tese (Doutorado em química) - Instituto de Química, Universidade Federal de Goiás, Goiás, 2009.

PARISOTO, M. F.; HILGER, T. R. Investigação da aprendizagem de conceitos de óptica utilizando ilusões para turmas de pré-vestibular. Revista Brasileira de Ensino de Ciências e Tecnologia., v. 9, n. 1, p. 62-98, jan.-abr. 2016.

RAU, M. C. T. D. A ludicidade na educação: uma atitude pedagógica. Curitiba: Intersaberes, 2007, 248p.

SOUZA, N. S.; PIRES, C. K.; LINHARES M. P. Ensino de química no PROEJA: uma proposta integradora das relações entre a sala de aula e um fórum virtual. Revista Virtual de Química. v. 7, n. 3, p. 992-10o6, maio-jun. 2015 .

USBERCO, J.; MARTINS, J. M.; SCHECHITMANN, E.; FERRER, L. C.; VELLOSO, H. M. Companhia das Ciências, $9^{\circ}$ ano. 4. ed. São Paulo: Saraiva, 2015, 277p.

WEISSMANN, H. (Org.). Didática das ciências naturais: contribuições e reflexões. ed.1. Porto Alegre: Artmed, 1998. 244P.

ZABEL, M.; SIPLE, I. Z. Experimento massa-mola: uma abordagem dinâmica para o ensino das funções. Revista Brasileira de Ensino de Ciência e Tecnologia. v. 6, n. 2, p.157-171, maio-ago. 2013.

Suelir Silva Ferreira: Licencianda em Ciências Naturais pela Universidade Federal do Maranhão. Possui curso-tecnicoprofissionalizante pelo Colégio Batista Professor Genésio Guimarães Lima de codó - MA (2010) e ensino-medio-segundo-grau pelo Centro de Ensino Médio Luzenir Matta Roma (2008).

E-mail:suelirsilvaferreira@gmail.com

Clara Virgínia Vieira Carvalho Oliveira Marques: Doutora em Química pela Universidade Federal de São Carlos- SP (2010. Professora adjunta III da Universidade Federal do Maranhão - Campus de Codó. É coordenadora do grupo de pesquisa em ensino de ciências naturais - GPECN e pesquisadora na linha de Educação, Ensino de Ciências e Ensino de Química, com ênfase na Formação de Professores de Ciências - Química e Ensino-Aprendizagem. Atualmente, é professora do quadro permanente do Programa de Pósgraduação em Ensino de Ciências e Matemática (PPECEM) e do Programa de Pós-Graduação em Gestão de Ensino na Educação Básica (PPGEEB).

E-mail: clara.marques@ufma.br

Paulo Roberto Brasil de Oliveira Marques: Professor Adjunto III, na Universidade Federal do Maranhão, Campus VII, Codó - MA. Atuou como membro do corpo docente e pesquisador do Mestrado em Química da UFMA. É membro do grupo de pesquisa NARP e vice-coordenador do grupo de pesquisa em ensino de ciências naturais-GPECN. Mestre em Química pela Universidade Federal do Maranhão e doutor em Química pela Universidade Estadual Paulista Júlio de Mesquita Filho em 2009. Efetua estudos colaborativos na área de ensino de ciências e na área de interdisciplinaridade.

E-mail: paulobrasilı@gmail.com 